\title{
INTERNAÇÕES CONSIDERADAS EVITÁVEIS POR DOENÇAS INFLAMATÓRIAS PÉLVICAS EM IDOSAS
}

Flávia Picoli Gheno; Pontifícia Universidade Católica do Rio Grande do Sul - PUCRS; flavia.brenda@gmail.com

Valéria Baccarin laniski; valeriaianiski@gmail.com

\section{RESUMO}

Introdução: $\mathrm{O}$ envelhecimento favorece alterações fisiológicas, funcionais e anatômicas em todo organismo feminino, comprometendo a qualidade de vida da mulher. Objetivo: Descrever a proporção de internações consideradas evitáveis por idosas com doenças inflamatórias pélvicas no Brasil, regiões e estados da federação. Métodos: Estudo quantitativo descritivo de dados extraídos do Sistema de Indicadores de Saúde e Acompanhamento de Políticas do Idoso, no ano de 2013 a 2018, provenientes do Sistema de Informações Hospitalares do Sistema Único de Saúde, em que foram incluídas idosas de 60 a 74 anos que receberam diagnóstico CID10 N70-76, causas definidas como sensíveis a atenção primária. Resultados: A proporção de internações consideradas evitáveis por idosas com doenças inflamatórias pélvicas foi de $0,11 \%$ no Brasil no período supracitado. A região Norte apresentou as maiores frequências de internações (2013:0,18\%;2014:0,16\%;2015:0,18\%;2016-2017:0,16\%;2018:0,23\%), ao passo que, a região Sul apresentou as menores frequências de internações consideradas evitáveis por idosas com doenças inflamatórias pélvicas (2013:0,08\%;2014-2015:0,09\%;2016-2017:0,08\%;2018:0,09\%), com exceção do ano de 2015 onde a região Centro-Oeste compartilhou da mesma frequência. Identificaram-se maiores frequências de internações evitáveis na Paraíba (2013:0,25\%), Mato Grosso (2014:0,28\%) e Acre (2015-2018:0,35;0,67;0,63;0,62\%) e as menores frequências nos estados da Bahia (2013:0,06\%), Pernambuco (2014:0,04\%), Roraima (2015-2016:0,00\%); Rondônia e Pernambuco $(2017: 0,05)$ e Rio Grande do Norte e Alagoas (2018:0,05\%). Conclusão: As regiões Norte e Sul apresentaram as maiores e menores frequências de internações consideradas evitáveis por idosas com doenças inflamatórias pélvicas. Dados sugerem incentivar a saúde da mulher nos estados do Norte e Nordeste visto estes apresentarem as maiores frequências de internações do período.

Palavras-chave: Doença inflamatória pélvica; Idoso; Mulheres; Sistema único de saúde.

Agradecimentos: Este trabalho foi realizado com apoio da Coordenação de Aperfeiçoamento de Pessoal de Nível Superior - Brasil (CAPES) - Código de Financiamento 001. 